\title{
Effect of dietary pomegranate seed oil and linseed oil on broiler chickens performance and meat fatty acid profile
}

\author{
B. Szymczyk ${ }^{1}$ and W. Szczurek \\ National Research Institute of Animal Production, Department of Animal Nutrition and Feed Science \\ 32-083 Balice, Poland
}

KEY WORDS: broilers, meat, pomegranate seed oil, linseed oil, punicic acid, CLA, n-6/n-3 PUFA

Received: $\quad 19$ May 2015

Revised: 30 December 2015

Accepted: 26 February 2016

${ }^{1}$ Corresponding author:

e-mail: beata.szymczyk@izoo.krakow.pl

\begin{abstract}
The effects of dietary pomegranate seed oil (PSO) and linseed oil (LO) on the growth performance, slaughter value and fatty acid (FA) profile of breast lipids of broiler chickens were investigated. A total of 400 one-day-old Ross 308 broilers were randomly assigned to 8 feeding treatments, with five replicates per treatment. Between $22-42$ day of life the birds were fed a grower type diets with four PSO levels: 0.0, 0.5, 1.0, 1.5\% and two levels of LO per PSO level: 0.0 and $2.0 \%$. In relation to the non-PSO diets, the feed-to-gain ratio in broilers fed PSO diets was improved $(P<0.01)$. Treatment with $1.5 \%$ dietary addition of PSO resulted in higher abdominal fat percentage in comparison to other PSO levels $(P<0.01)$. Increasing amounts of PSO in the diet caused a gradual rise in the deposition of conjugated linoleic acid isomers (CLA) in breast lipids. The share of saturated fatty acids in breast lipids did not differ, whereas the share of polyunsaturated fatty acids (PUFA) increased $(P<0.01)$ and the share of monounsaturated fatty acids (MUFA) decreased $(P<0.01)$. Compared to the non-LO diets, the $2 \%$ LO addition significantly increased total PUFA, decreased total MUFA proportions and improved $n-6 / n-3$ ratio in this tissue. It is concluded, that feeding broiler chickens with diet supplemented with PSO results in a substantial incorporation of CLA isomers into breast lipids and gives a favourable shifts in FA profile of these lipids which could be additionally modulated by $\mathrm{LO}$ addition.
\end{abstract}

\section{Introduction}

The use of nutritional strategies to improve the composition and quality of food products of animal origin has emerged recently at the interface of animal science, food science and human nutrition. This new approach has been effectively used to alter product composition to be functional (i.e. health-promoting). For example, feeding broiler chickens with conjugated linoleic acid (CLA; 9c,12cC18:2n-6 positional and geometric isomers), which health benefits have been already confirmed, is an effective way to obtain CLA-enriched poultry meat.
However, the CLA supplements adversely affect the fatty acid composition of muscle lipids by increasing their saturated fatty acids content at the expense of monounsaturated and polyunsaturated fatty acids. Moreover, the broilers fed CLA supplemented diets exhibited impaired growth performance (Szymczyk et al., 2001). In addition, feeding broiler chickens with incremental levels of CLA $(0.0,0.5,1.0$ and $1.5 \%)$ resulted not only in linear increases in CLA isomers levels but also in decreases in the level of $\alpha$-linolenic acid (ALA; 9c,12c,15c-C18:3n-3). Consequently, the ratio of $n-6 / n-3$ polyunsaturated fatty acids (PUFA) unfavourably increased. Recent 
reports suggest high biological activity of conjugated linolenic acid (CLnA 9c;12c,15c-C18:3n-3 positional and geometric isomers) found in different plant seeds. Five CLnA isomers at least have been found in nature: $\alpha$-eleostearic acid $(9 \mathrm{c}, 11 \mathrm{t}, 13 \mathrm{t}-\mathrm{C} 18: 3 \mathrm{n}-3)$, catalpic acid $(9 \mathrm{c}, 11 \mathrm{t}, 13 \mathrm{c}-\mathrm{C} 18: 3 \mathrm{n}-3)$, calendic acid (9c,10t,12c-C18:3n-3), jacaric acid $(8 \mathrm{c}, 10 \mathrm{t}, 12 \mathrm{c}-$ C18:3n-3) and punicic acid (9c,11t,13c-C18:3n-3) (Koba et al., 2007). CLnA isomers have been attributed to exhibit several health benefits that are largely based on animal and in vitro studies (Boussetta et al., 2009; Hontecillas et al., 2009; Hennessy et al., 2011; Saha and Ghos, 2012; Yuan et al., 2014).

Punicic acid is found in high amounts in pomegranate (Punica granatum L.) seed oil (PSO). It was stated that PSO reduced body weight gain, and leptin and insulin levels in pathogen-free mice (McFarlin et al., 2009). It was also observed that PSO supplementation in diet improves glucose tolerance and suppresses obesity related inflammation (Hontecillas et al., 2009). PSO was also shown to exhibit in vivo antioxidant and anti-inflammatory activities by limiting neutrophil-activation and lipid peroxidation (Melo et al., 2014) and it has been reported to promote epidermal tissue regeneration (Sassano et al., 2009). Punicic acid from PSO also has a cytotoxic effect on a cultured human tumour cell. It can suppress colon and skin carcinogenesis in vivo and suppress proliferation, growth and invasion of human prostate and breast cancer cells (Kohno et al., 2004; Igarashi and Miyazawa, 2005; Yasui et al., 2005; Grossmann et al., 2010).

In vitro mice, rat and human studies have shown that some CLnA isomers may be converted into CLA, whose health-promoting effects have been better characterized and reported in many previous studies. Conversion of CLnA into CLA was observed in rats fed jacaric acid (Tsuzuki et al., 2006), and also in mice, rats (Koba et al., 2007; Yuan et al., 2009b,c) and humans fed punicic acid (Yuan et al., 2014). In view of the above-mentioned healthrelated effects of conjugated fatty acids (CLA), it seems desirable to provide CLnA- and CLA-enriched products for human consumption.

However, the possibility of punicic acid of incorporation into various animal tissues has not been definitely confirmed yet (Nekooeian et al., 2014; Yuan et al., 2014). It is possible, as in the case of dietary CLA, that diet supplementation with PSO and expected conversion of punicic acid into CLA in broilers may result in increasing n-6 PUFA level in broiler tissue lipids, and consequently, in the deterioration of the n-6/n-3 PUFA ratio. On the other hand, results of previous studies demonstrated that linseed oil (LO) is a good source of ALA and it can be successfully used for enriching poultry meat with n-3 fatty acids, and thus for obtaining more desirable ratio of $n-6$ to $n-3$ PUFA. The latter was clearly confirmed for amount of LO supplementation ranging from 1.25 to $5.5 \%$ of diet (Jankowski et al., 2012; Chen et al., 2014).

Therefore, the aim of this study was to determine the possibilities of enriching poultry with punicic acid and CLA isomers by the addition of PSO and LO at the expense of rapeseed oil to the broiler chickens feed, which could improve n-6/n-3 PUFA ratio in the meat.

\section{Material and methods}

\section{Birds, housing and feeding}

The experiment was conducted at the Experimental Station of the National Research Institute of Animal Production in Balice. All experimental procedures were reviewed and approved by the $2^{\text {nd }}$ Local Ethics Committee for Animal Experimentation in Krakow. Four hundred feather-sexed one-dayold chickens (sex ratio 1:1) of a commercial strain Ross 308 were housed in electrically heated battery brooders. The temperature inside the building was maintained at $32^{\circ} \mathrm{C}$ from day 1 to 5 and then gradually

\begin{tabular}{|c|c|}
\hline Indices & $\mathrm{g} \cdot \mathrm{kg}^{-1}$ air dry matter \\
\hline \multicolumn{2}{|l|}{ Component } \\
\hline wheat & 197.0 \\
\hline maize & 410.0 \\
\hline soyabean meal & 300.0 \\
\hline rapeseed oil & 50.0 \\
\hline limestone & 11.5 \\
\hline dicalcium phosphate & 20.0 \\
\hline $\mathrm{NaCl}$ & 3.0 \\
\hline vitamin-mineral premix ${ }^{1}$ & 5.0 \\
\hline DL-Met (99\%) & 2.0 \\
\hline L-Lys-HCl (78\%) & 1.5 \\
\hline \multicolumn{2}{|l|}{ Calculated nutrient content ${ }^{2}$} \\
\hline $\mathrm{ME}, \mathrm{MJ} \cdot \mathrm{kg}^{-1}$ & 12.6 \\
\hline crude protein & 198.0 \\
\hline methionine & 5.0 \\
\hline lysine & 11.1 \\
\hline $\mathrm{Ca}$ & 9.7 \\
\hline$P$ available & 4.1 \\
\hline
\end{tabular}

provided per kg of diet: IU: vit. A 12000, vit. $D_{3} 3250$; mg: vit. E 40, vit. $K 2.25$, vit. $B_{1} 2$, vit. $B_{2} 7.25$, vit. $B_{6} 4.25$, vit. $B_{12} 0.03$, biotin 0.1 , folic acid 1, nicotinic acid 40 , calcium pantothenate 12 , choline chloride 450, Fe 65, Zn 65, Mn 100, Cu 15, I 0.8, Se 0.25, Co 0.4; ${ }^{2}$ calculated from tabular data on proximate composition of feed materials (Smulikowska and Rutkowski, 2005) and energy value calculated using formulas according to Subcommittee Energy of the Working Group nr. 2 Nutrition of the European Federation of Branches of the World's Poultry Science Association (1989) 
Table 2. Experimental scheme

\begin{tabular}{lll}
\hline \multirow{2}{*}{ Diet } & \multicolumn{2}{l}{ Dietary levels, $\%{ }^{1}$} \\
\cline { 2 - 3 } & PSO & LO \\
\hline 1 & 0.0 & 0.0 \\
2 & 0.5 & 0.0 \\
3 & 1.0 & 0.0 \\
4 & 1.5 & 0.0 \\
5 & 0.0 & 2.0 \\
6 & 0.5 & 2.0 \\
7 & 1.0 & 2.0 \\
8 & 1.5 & 2.0 \\
\hline
\end{tabular}

${ }^{1}$ pomegranate seed oil (PSO) and linseed oil (LO) were added to the basal experimental diet (Table 1) at the expense of rapeseed oil

reduced to $22^{\circ} \mathrm{C}$ until the end of rearing ( 42 day of life). The lighting cycle was set to provide $18 \mathrm{~h}$ of light and $6 \mathrm{~h}$ of dark per day. The chickens were randomly allocated to eight groups with equal number of males and females. There were five replications for each group, and each replicate cage contained 5 males and 5 females. During the pre-experimental phase (from day 1 to 21) all birds were given ad libitum access to a mash starter type diet based on maize, wheat and soyabean meal $\left(22.3 \% \mathrm{CP}\right.$ and $\left.12.5 \mathrm{MJ} \mathrm{ME} \cdot \mathrm{kg}^{-1}\right)$. From 22 to 42 day of life the birds received ad libitum a grower type diet (Table 1) in which pomegranate seed oil (PSO) (58.83\% punicic acid) and linseed oil (LO) $(56.78 \% \alpha$-linolenic acid) were included at the expense of rapeseed oil. Eight dietary treatments consisting of four graded levels $(0.0,0.5,1.0$ and $1.5 \%)$ of PSO, with or without $2 \%$ addition of LO were tested (Table 2). Fatty acid profile of treatment diets is given in Table 3 (as a percentage of the sum of fatty acids identified by analyses).

\section{Measurements, sampling and calculations}

The chickens were weighed by replicate cage at the 21 and 42 day of life after $4 \mathrm{~h}$ of feed deprivation. Body weight gain (BWG) was calculated for $22-42$ days rearing period, and feed intake was measured in order to calculate the feed conversion ratio (FCR).

At 42 day of life, 5 representative males and 5 females from each treatment were chosen and weighed after $12 \mathrm{~h}$ of feed deprivation. The birds were then stunned, slaughtered by cervical dislocation and exsanguinated. The carcasses were plucked, eviscerated, the head and feet were removed. Abdominal fat, breast and leg muscles, liver, gizzard and heart were excised and weighted. Carcass yield was calculated as the ratio of the eviscerated carcass mass to live body weight (LBW). The weights of the breast and leg muscles, abdominal fat, liver, gizzard and heart were also calculated in relation to LBW.

Samples of breast (pectoralis major and pectoralis minor) muscles from carcasses of all male chicken were stored frozen $\left(-25^{\circ} \mathrm{C}\right)$ for the analysis of fatty acids profile.

\section{Analytical methods}

The total lipids in treatment diets and meat samples were extracted according to the method of Folch et al. (1957). They were saponified $\left(10 \mathrm{~min}, 75^{\circ} \mathrm{C}\right.$ ) in $0.5 \mathrm{M} \mathrm{KOH}$ in methanol and then

Table 3. Fatty acid profile of treatment diets, $\mathrm{g} \cdot 100 \mathrm{~g}^{-1}$ of fatty acids ${ }^{1}$

\begin{tabular}{|c|c|c|c|c|c|c|c|c|}
\hline \multirow{2}{*}{ Fatty acid } & \multicolumn{8}{|l|}{ Diet $^{2}$} \\
\hline & 1 & 2 & 3 & 4 & 5 & 6 & 7 & 8 \\
\hline $\mathrm{C} 12: 0$ & 0.04 & 0.02 & 0.00 & 0.01 & 0.05 & 0.02 & 0.03 & 0.03 \\
\hline $\mathrm{C} 14: 0$ & 0.07 & 0.10 & 0.09 & 0.07 & 0.12 & 0.10 & 0.16 & 0.15 \\
\hline C16:0 & 9.75 & 7.89 & 8.15 & 8.29 & 8.33 & 8.89 & 9.28 & 9.27 \\
\hline C16:1 & 0.19 & 0.18 & 0.15 & 0.17 & 0.22 & 0.25 & 0.05 & 0.21 \\
\hline C18:0 & 2.82 & 2.91 & 2.96 & 3.09 & 3.24 & 2.59 & 2.38 & 2.51 \\
\hline C18:1 & 45.62 & 45.12 & 42.71 & 40.47 & 34.66 & 32.48 & 29.97 & 27.09 \\
\hline C18:2 n-6 & 32.92 & 30.51 & 29.22 & 27.63 & 32.46 & 32.33 & 31.07 & 29.95 \\
\hline C18:3 n-3 & 7.61 & 7.72 & 7.02 & 6.24 & 19.72 & 18.19 & 17.94 & 18.02 \\
\hline $9 c, 11 t, 13 c-C 18: 3 n-6^{3}$ & 0.00 & 4.12 & 8.26 & 10.99 & 0.00 & 3.99 & 8.06 & 11.29 \\
\hline $\mathrm{C} 20: 0$ & 0.47 & 0.63 & 0.62 & 0.58 & 0.53 & 0.54 & 0.47 & 0.65 \\
\hline $\mathrm{C} 22: 0$ & 0.39 & 0.51 & 0.51 & 0.45 & 0.48 & 0.46 & 0.39 & 0.46 \\
\hline $\mathrm{C} 22: 1$ & 0.14 & 0.29 & 0.31 & 0.35 & 0.21 & 0.19 & 0.24 & 0.37 \\
\hline $\mathrm{SFA}^{4}$ & 13.54 & 12.06 & 12.33 & 12.49 & 12.75 & 12.63 & 12.71 & 13.07 \\
\hline MUFA $^{5}$ & 45.93 & 45.59 & 43.17 & 40.99 & 35.09 & 32.92 & 30.26 & 27.67 \\
\hline PUFA $^{6}$ & 40.53 & 42.35 & 44.54 & 44.86 & 52.16 & 54.48 & 57.03 & 59.26 \\
\hline n-6PUFA & 32.92 & 30.51 & 29.22 & 27.63 & 32.46 & 32.30 & 31.07 & 29.95 \\
\hline n-3PUFA & 7.61 & 11.84 & 15.28 & 17.23 & 19.71 & 22.18 & 25.96 & 29.31 \\
\hline$n-6 / n-3 P U F A$ & 4.32 & 2.57 & 1.91 & 1.60 & 1.64 & 1.45 & 1.19 & 1.02 \\
\hline
\end{tabular}


methylated $\left(10 \mathrm{~min}, 75^{\circ} \mathrm{C}\right)$ in $14 \%(\mathrm{v} / \mathrm{v}) \mathrm{BF}_{3}$ in methanol (Morrison and Smith, 1964). Finally, fatty acid methyl esters were extracted with hexane and analysed on a Shimadzu 2010 gas chromatograph (Shimadzu Corp., Kyoto, Japan) equipped with a RTX2330 fused silica capillary column (105 m length, $0.32 \mathrm{~mm}$ inner diameter, $0.20 \mu \mathrm{m}$ film thickness; Restek Corp., Bellefonte, PA, USA). Fatty acid methyl esters were identified by comparison of their retention times with positional and geometric isomers according to the standards purchased from Sigma-Aldrich (St. Louis, MO, USA); the CLA and punicic acid reference standards were obtained from Larodan Fine Chemicals AB (Malmö, Sweden).

\section{Statistical analysis}

The replicate cage served as the experimental unit for growth performance indices $(\mathrm{n}=5)$, and individual birds were the experimental units for statistical analysis of carcass characteristic $(n=10$, both sexes) and fatty acids profile ( $\mathrm{n}=5$, males) data. Statistical evaluation of all of the results was conducted with the Statistica ${ }^{\circledR} 10.0$ package (StatSoft Inc., 2010, Tulsa, OK, USA). The main effects of dietary treatments and their interactions were determined by two-way ANOVA. The effect of sex was included in the model when analysing postslaughter variables. For production data this was not possible since these results were cage means. If the probability value of F-tests was $<0.1$, differences among main effect means were determined with the Duncan's post-hoc test and the level of significance was set at $P<0.01$.

\section{Results}

\section{Growth performance and post-slaughter indices}

The average body weight of mixed-sex chickens before the initiation of the experimental period (21 day of life) was $602 \pm 6 \mathrm{~g}$. Over the experimental phase (22-42 day), the body weight gain (BWG) of birds fed diets supplemented with increasing amounts of pomegranate seed oil (PSO) did not differ (Table 4). Nevertheless, the feed conversion ratio (FCR) was better in the groups with $0.5,1.0$ and $1.5 \%$ PSO in relation to groups fed diets without PSO $(P<0.01)$. There were no significant effects of dietary LO on BWG and FCR.

Generally, no effects of dietary PSO and LO on broiler carcass characteristics were found; carcass yield, proportions of breast and leg muscles, and the liver, gizzard and heart relative weights did not differ among groups (Table 5). The only exception
Table 4. Main effects of dietary inclusion of pomegranate seed oil (PSO) and linseed oil (LO) on production parameters of mixed-sex chickens between 22 and 42 day of life

\begin{tabular}{|c|c|c|c|}
\hline Main effect & $\begin{array}{l}\text { FBW }^{1} \\
\mathrm{~g}\end{array}$ & $\begin{array}{l}\mathrm{BWG}^{2}, \\
\mathrm{~g}\end{array}$ & $\begin{array}{l}\mathrm{FCR}^{3}, \\
\mathrm{~g} \text { feed per g BWG }\end{array}$ \\
\hline \multicolumn{4}{|c|}{ Dietary PSO, \% } \\
\hline 0.0 & 2560 & 1953 & $1.96^{\mathrm{a}}$ \\
\hline 0.5 & 2554 & 1946 & $1.85^{b}$ \\
\hline 1.0 & 2544 & 1947 & $1.86^{b}$ \\
\hline 1.5 & 2563 & 1967 & $1.86^{b}$ \\
\hline$P$-value & 0.866 & 0.231 & 0.003 \\
\hline \multicolumn{4}{|l|}{ Dietary LO, \% } \\
\hline 0.0 & 2557 & 1955 & 1.89 \\
\hline 2.0 & 2554 & 1952 & 1.87 \\
\hline$P$-value & 0.770 & 0.196 & 0.195 \\
\hline Pooled SEM & 70.33 & 29.11 & 0.013 \\
\hline \multicolumn{4}{|c|}{ Interactions ( $P$-value) } \\
\hline PSO $\times$ LO & 0.706 & 0.058 & 0.077 \\
\hline
\end{tabular}

${ }^{1}$ final body weight at 42 day of life; ${ }^{2}$ body weight gain; ${ }^{3}$ feed conversion ratio; ${ }^{a b}$ - values with different superscripts within columns for each main effect separately differ significantly at $P<0.01$

was abdominal fat percentage found to be higher $(P<0.05)$ in broilers fed diet with $1.5 \%$ PSO addition in comparison to groups fed diet with 0 and $0.5 \%$ PSO content. As it was expected, the abdominal fat deposition in females was significantly higher than in male chickens $(P<0.01)$. No significant interactions $(\mathrm{PSO} \times \mathrm{LO})$ on growth performance and slaughter characteristics were detected.

\section{Fatty acid profile of breast muscle lipids}

Fatty acids compositions of breast muscles of male chickens, expressed as a percentage of total methyl esters of fatty acids, were significantly altered by increasing dietary PSO concentrations (Table 6). Increasing amounts of PSO in the diet caused a gradual rise in the deposition of CLA isomers (mainly 9c,11t-C18:2n-6) in muscle lipids, but punicic acid was not found. There were no statistical differences between treatments in the level of saturated fatty acids (SFA). The share of PUFA was significantly higher, and the share of monounsaturated fatty acids (MUFA) was lower $(P<0.01)$ in broilers treated with PSO at the 1.0 and $1.5 \%$ when compared to other dietary levels 0.0 and $0.5 \%$. Among MUFA oleic (C18:1) acid deposition was decreased, and among PUFA eicosapentaenoic acid (EPA; C20:5n-3) was increased in all experimental treatments $(P<0.01)$, whereas the levels of arachidonic acid (C20:4n-6) and docosahexaenoic acid (DHA; C22:6n-3) were significantly increased in tissues from broilers fed diet with 1.0 and $1.5 \%$ PSO addition compared to group fed diet with 0.0 and $0.5 \%$ PSO content. Compared to the nonLO diets, the $2.0 \%$ LO in feed significantly increased 
Table 5. Main effects of dietary inclusion of pomegranate seed oil (PSO) and linseed oil (LO), and sex (S) on post-slaughter characteristics of chickens at 42 day of life, $\%$ of body weight

\begin{tabular}{|c|c|c|c|c|c|c|c|}
\hline Main effect & $\begin{array}{l}\text { Carcass } \\
\text { yield }\end{array}$ & $\begin{array}{l}\text { Breast } \\
\text { meat }\end{array}$ & $\begin{array}{l}\text { Leg } \\
\text { meat }\end{array}$ & $\begin{array}{l}\text { Abdominal } \\
\text { fat }\end{array}$ & Liver & Gizzard & Heart \\
\hline \multicolumn{8}{|l|}{ Dietary PSO,\% } \\
\hline 0.0 & 72.6 & 22.7 & 15.3 & $1.18^{b}$ & 1.59 & 0.96 & 0.40 \\
\hline 0.5 & 72.1 & 22.7 & 15.6 & $1.13^{b}$ & 1.55 & 0.97 & 0.38 \\
\hline 1.0 & 72.7 & 22.5 & 15.6 & $1.29^{a b}$ & 1.62 & 0.96 & 0.40 \\
\hline 1.5 & 72.6 & 22.1 & 15.4 & $1.48^{\mathrm{a}}$ & 1.65 & 0.89 & 0.42 \\
\hline$P$-value & 0.724 & 0.181 & 0.862 & 0.013 & 0.409 & 0.055 & 0.393 \\
\hline \multicolumn{8}{|l|}{ Dietary LO, \% } \\
\hline 0.0 & 72.4 & 22.3 & 15.5 & 1.32 & 1.61 & 0.94 & 0.39 \\
\hline 2.0 & 72.6 & 22.7 & 15.5 & 1.22 & 1.60 & 0.95 & 0.41 \\
\hline$P$-value & 0.729 & 0.070 & 0.914 & 0.183 & 0.804 & 0.804 & 0.152 \\
\hline \multicolumn{8}{|l|}{ Sex } \\
\hline male & 72.3 & 22.2 & 15.5 & $1.06^{b}$ & 1.56 & 0.96 & 0.39 \\
\hline female & 72.7 & 22.8 & 15.5 & $1.48^{\mathrm{a}}$ & 1.65 & 0.93 & 0.41 \\
\hline$P$-value & 0.325 & 0.067 & 0.953 & $<0.000$ & 0.054 & 0.307 & 0.225 \\
\hline Pooled SEM & 0.665 & 0.702 & 0.422 & 0.149 & 0.065 & 0.034 & 0.023 \\
\hline \multicolumn{8}{|c|}{ Interactions ( $P$-value) } \\
\hline PSO × LO & 0.253 & 0.621 & 0.373 & 0.134 & 0.137 & 0.750 & 0.842 \\
\hline $\mathrm{PSO} \times \mathrm{LO} \times \mathrm{S}$ & 0.535 & 0.081 & 0.611 & 0.290 & 0.235 & 0.719 & 0.342 \\
\hline PSO $\times S$ & 0.723 & 0.189 & 0.415 & 0.017 & 0.724 & 0.237 & 0.889 \\
\hline $\mathrm{LO} \times \mathrm{S}$ & 0.546 & 0.557 & 0.588 & 0.052 & 0.216 & 0.478 & 0.202 \\
\hline
\end{tabular}

${ }^{\text {ab }}$ - values with different superscripts within columns for each main effect separately are significantly different at $P<0.05$

Table 6. Main effects of dietary inclusion of pomegranate seed oil (PSO) and linseed oil (LO) on the fatty acids profile in breast muscle of male broiler chickens, $\mathrm{g} \cdot 100 \mathrm{~g}^{-1}$ of fatty acids

\begin{tabular}{|c|c|c|c|c|c|c|c|c|}
\hline \multirow{2}{*}{ Fatty acid } & \multicolumn{4}{|c|}{ Dietary PSO, \% } & \multicolumn{2}{|c|}{ Dietary LO, \% } & \multirow{2}{*}{$\begin{array}{l}\text { Pooled } \\
\text { SEM }\end{array}$} & \multirow{2}{*}{$\begin{array}{l}\text { PSO } \times \text { LO } \\
(P \text {-value })\end{array}$} \\
\hline & 0.0 & 0.5 & 1.0 & 1.5 & 0.0 & 2.0 & & \\
\hline $\mathrm{C} 14: 0$ & 0.45 & 0.43 & 0.38 & 0.39 & 0.42 & 0.43 & 0.012 & 0.029 \\
\hline C16:0 & 17.94 & 18.36 & 18.04 & 17.63 & $17.61^{y}$ & $19.37^{x}$ & 0.478 & $<0.000$ \\
\hline C16:1 & 1.34 & 1.56 & 1.38 & 1.20 & 1.25 & 1.45 & 0.045 & 0.004 \\
\hline C18:0 & 8.87 & 8.90 & 9.30 & 9.12 & 8.91 & 9.19 & 0.517 & 0.026 \\
\hline C18:1 & $32.92^{\mathrm{a}}$ & $32.30^{\mathrm{a}}$ & $28.56^{b}$ & $27.73^{c}$ & $31.79^{x}$ & $29.97^{y}$ & 0.789 & 0.105 \\
\hline C18:2 n-6 & 19.27 & 19.48 & 19.75 & 19.08 & 19.39 & 19.41 & 0.547 & 0.155 \\
\hline C18:3n-6 & 0.24 & 0.17 & 0.12 & 0.12 & 0.14 & 0.18 & 0.005 & 0.277 \\
\hline C18:3 n-3 & 4.66 & 4.46 & 4.00 & 4.55 & $2.56^{y}$ & $6.00^{x}$ & 0.011 & 0.002 \\
\hline $9 c, 11 \mathrm{t}-\mathrm{CLA}$ & $0.74^{d}$ & $1.87^{\circ}$ & $2.78^{b}$ & $4.47^{\mathrm{a}}$ & $2.65^{x}$ & $2.28^{y}$ & 0.009 & $<0.000$ \\
\hline $9 c, 11 c-C L A$ & $0.03^{c}$ & $0.07^{c}$ & $0.14^{b}$ & $0.27^{\mathrm{a}}$ & 0.13 & 0.13 & 0.002 & 0.048 \\
\hline 9t,11t-CLA & $0.05^{d}$ & $0.14^{c}$ & $0.24^{b}$ & $0.36^{a}$ & 0.20 & 0.19 & 0.002 & 0.009 \\
\hline CLA total & $0.82^{\mathrm{d}}$ & $2.08^{c}$ & $3.16^{b}$ & $5.10^{\mathrm{a}}$ & 2.98 & 2.60 & 0.012 & 0.506 \\
\hline C20:0 & 0.15 & 0.18 & 0.15 & 0.16 & 0.16 & 0.16 & 0.009 & 0.505 \\
\hline C22:0 & 0.13 & 0.14 & 0.14 & 0.14 & 0.13 & 0.15 & 0.001 & 0.003 \\
\hline C20:4 n-6 & $9.82^{b}$ & $8.77^{\circ}$ & $10.36^{a}$ & $10.15^{\mathrm{a}}$ & $11.34^{x}$ & $8.20^{y}$ & 0.025 & 0.011 \\
\hline C22:1 & 0.10 & 0.08 & 0.08 & 0.08 & 0.09 & 0.08 & 0.000 & 0.025 \\
\hline C20:5 n-3 & $1.19^{c}$ & $1.57^{b}$ & $1.71^{\mathrm{b}}$ & $2.14^{\mathrm{a}}$ & $1.18^{y}$ & $2.12^{x}$ & 0.011 & 0.104 \\
\hline C22:6 n-3 & $2.10^{b}$ & $1.85^{b}$ & $2.48^{a}$ & $2.41^{a}$ & $1.95^{y}$ & $2.47^{x}$ & 0.010 & 0.004 \\
\hline SFA & 27.54 & 27.67 & 28.42 & 27.46 & 27.31 & 28.24 & 0.267 & 0.018 \\
\hline MUFA & $34.36^{\mathrm{a}}$ & $33.94^{b}$ & $30.05^{c}$ & $28.98^{d}$ & $33.13^{x}$ & $31.50^{y}$ & 0.682 & 0.068 \\
\hline PUFA & $38.10^{c}$ & $38.39^{c}$ & $41.53^{b}$ & $43.56^{a}$ & $39.56^{y}$ & $40.26^{x}$ & 1.130 & 0.001 \\
\hline n-6PUFA & 30.15 & 30.05 & 33.39 & 34.49 & $33.85^{x}$ & $30.39 y$ & 0.781 & 0.004 \\
\hline n-3PUFA & $7.95^{c}$ & $7.88^{c}$ & $8.19^{b}$ & $9.10^{a}$ & $5.69^{y}$ & $10.59^{x}$ & 0.009 & $<0.000$ \\
\hline$n-6 / n-3 P U F A$ & 3.79 & 3.87 & 4.07 & 3.78 & $5.94^{x}$ & $2.89^{y}$ & 0.002 & 0.002 \\
\hline
\end{tabular}

SFA, MUFA, PUFA - see Table 3; abcd and ${ }^{x y}$ - values with different superscripts (abcd for PSO and ${ }^{x y}$ for LO) within rows are significantly different at $P<0.01$ 
total PUFA and decreased total MUFA proportions in the breast muscles. These changes resulted mainly from the rise in deposition of ALA, EPA, DHA, and from fall in the content of oleic acid. Higher level of n-3 fatty acids (ALA, DHA and EPA) in meat tissue improved n-6/n-3 PUFA ratio $(P<0.01)$. No significant differences were found in the average ratio of n-6 to n-3 PUFA for chickens fed diets with PSO addition. However, an interaction between the main effects of PSO and LO $(P=0.002)$ showed a clear improvement in $n-6 / n-3$ PUFA ratio in the case of feeding $1.5 \%$ PSO diet enriched with LO. Significant PSO $\times$ LO interactions within the levels of individual fatty acids were observed. Namely, CLA isomers (9c,11t- and 9c,11c-C18:2n-6) were incorporated into breast lipids less efficiently in broiler chickens fed diets with simultaneous addition of PSO and LO compared to chickens fed PSO only. In contrast, feeding PSO with co-added LO resulted in a considerably higher incorporation of DHA and EPA into meat lipids than feeding of PSO or LO as separate supplements (Table 6).

\section{Discussion}

In the present study no significant differences were found in body weight gain of broilers fed pomegranate seed oil (PSO) at the chosen dietary levels. This confirms the results of Nekooeian et al. (2014), who found that 200 or $600 \mathrm{mg} \cdot \mathrm{kg}^{-1}$ PSO per day did not cause significant changes in the weight of diabetic rats. Yuan et al. (2009b) showed that diet supplemented with $1.0 \%$ conjugated linolenic acid (CLnA) isomers ( $\alpha$-eleostearic and/or punicic acid) fed for 6 weeks did not significantly affect the body mass of mice. In contrast, Chin et al. (1994) reported that conjugated linoleic acid (CLA) is a dietary factor enhancing rats growth. In the study of Arao et al. (2004) with obese, hyperlipidaemic Otsuka LongEvans Tokushima Fatty (OLETF) rats, dietary PSO reduced weight of omental white adipose tissues, but not that of abdominal white adipose tissue. Our study has shown a significant improvement in feed conversion ratio by the dietary PSO. In contrast, Szymczyk et al. (2001) found that feed conversion efficiency tended to decrease in chickens fed diets with increasing levels of CLA.

In this study we have confirmed that the dietary linseed oil (LO) did not affect $22-42$ days growth rate of chickens and their carcass yield. Similar effects of replacing maize or soyabean oils with LO in chicken diets were reported by Chen et al. (2014) and Crespo and Esteve-Garcia (2001). Moreover, Jankowski et al. (2012) observed no difference in dressing percentage, and breast, thigh and drumstick muscle yield in turkeys fed diets with soyabean, rapeseed or linseed oils.

In the current study the punicic acid in the lipids from breast muscles of chickens fed diets with PSO addition was not detected, while the CLA isomers levels were significantly and dose-dependently higher in comparison to the non-PSO groups. These findings are in line with other reports (Kohno et al., 2004; Koba et al., 2007; Yuan et al., 2009c; Melo et al., 2014). The data obtained by these authors suggest that punicic acid is slowly absorbed in the rat and mice intestine, but it can be converted into 9c, 11t-C18:2n-6 in various tissues, e.g., liver, adipose, kidney and brain. Moreover, punicic acid can be incorporated into plasma and red blood cells, and partially metabolized into CLA in humans (Tsuzuki et al., 2006). These authors found that punicic acid was incorporated into plasma ( $0.47 \%$ total fatty acids (FA)) and red blood cell membranes (RBCM) $(0.37 \%$ total FA) in humans after supplementation with $3 \mathrm{~g}$ punicic acid per day for 28 days. The proportions of 9c,11t-C18:2n-6 in plasma and RBCM increased to 0.23 and $0.17 \%$, respectively. The in vivo mechanism of punicic acid conversion into CLA is not clear. Some studies suggest that conjugated linolenic acid (CLnA) isomers may be converted into 9c, 11t-C18:2n-6 via $\Delta 13$-saturation reaction (Tsuzuki et al., 2006; Yuan et al., 2009a). However, the enzyme that catalyses the reaction of $\Delta 13$-saturation in animals and humans has not been identified yet. It was suggested that a nicotinamide adenine dinucleotide phosphate-dependent enzyme which is either a novel enzyme recognizing CLnA or the enzyme that is active in the leukotriene B4 reductive pathway could have carried this $\Delta 13$-saturation reaction in rats and mice (Tsuzuki et al., 2006; Yuan et al., 2009c).

The present study showed no significant effect of dietary PSO and LO on saturated fatty acids (SFA) deposition in the meat of chickens. Similar effects for PSO were reported by Arao et al. (2004) in serum triacylglycerol in OLETF rats, and by Kohno et al. (2004) in rat livers. In contrast, Jankowski et al. (2012) showed that, in comparison to dietary soyabean oil, LO to decreases the SFA level in turkey breast muscles. On the other hand, feeding CLA to broiler chickens significantly increased the relative proportion of SFA in the meat (Szymczyk et. al., 2001).

In our experiment, the share of monounsaturated fatty acids (MUFA; mainly C18:1) in breast muscles decreased significantly due to presence of both PSO and LO in the diet. Similar results were reported for chickens fed diets with Camelina sativa oil 
(Pietras and Orczewska-Dudek, 2013) and for turkeys fed diets supplemented with linseed oil (Jankowski et al., 2012). Kohno et al. (2004) showed that dietary CLA or CLnA from PSO reduced slightly, but not significantly, oleic acid level in rats livers. Also Szymczyk et al. (2001) showed that feeding CLA to chickens reduced MUFA level in the meat lipids. Most probably the significant reduction of oleic acid and the increase in stearic acid share in the breast muscles of chickens observed in the above mentioned experiment was related to n-3 PUFA and CLA inhibitory effect on the activity of $\Delta 9$-desaturase, an enzyme which is responsible for the conversion of stearic acid into oleic acid in the liver (Palmquist, 2009).

In the present experiment we found that dietary linseed oil significantly increased n-3 PUFA (ALA, EPA and DHA) deposition in breast muscles. This confirms the results obtained in chickens (Chen et al., 2014) and turkeys (Jankowski et al., 2012). Also Pietras and Orczewska-Dudek (2013) found that Camelina sativa oil used in broiler diets as a source of ALA resulted in increased level of DHA and EPA in the breast muscle. The present study has also demonstrated that the concentration of EPA and DHA in the breast lipids of chickens is enhanced by the feeding of punicic acid. This phenomenon is probably due to the fact that chickens have the unusual ability to convert a small portion of dietary ALA to EPA, involving sequential $\Delta 6$-desaturation, chain elongation, and $\Delta 5$-desaturation. Subsequently, EPA is converted to DHA (Yuan et al., 2009b). In the present study, total n-3 PUFA level was significantly increased in chickens fed LO and the n-6/n-3 PUFA ratio was significantly improved. Our results are consistent with those observed in turkeys fed LO (Jankowski et al., 2012) and in chickens fed Camelina sativa oil-supplemented diets (Pietras and Orczewska-Dudek, 2013).

\section{Conclusions}

Feeding pomegranate seed oil (PSO) to broiler chickens results in a substantial incorporation of conjugated linoleic acid isomers into the breast meat lipids and gives a favourable shifts in fatty acid profile of these lipids, maintaining competitive production traits of meat. Linseed oil supplementation of the PSO-containing diets can additionally improve the $n-6 / n-3$ polyunsaturated fatty acids ratio in chicken breast lipids.

\section{References}

Arao K., Wang Y.M., Inoue N., Hirata J., Cha J.Y., Nagao K., Yanagita T., 2004. Dietary effect of pomegranate seed oil rich in 9cis, 11 trans, 13 cis conjugated linolenic acid on lipid metabolism in obese, hyperlipidemic OLETF rats. Lipids Health Dis. 3, 24, doi:I.0.|I86//476-5IIX-3-24

Boussetta T., Raad H., Lettéron P., Gougerot-Pocidalo M.A., Marie J.C., Driss F., El-Benna J., 2009. Punicic acid a conjugated linolenic acid inhibits TNFalpha-induced neutrophil hyperactivation and protects from experimental colon inflammation in rats. PLoS One 4, e6458, doi:10.1371/journal.pone.0006458

Chen W., Zhao R., Yan B.X., Zhang J.S., Huang Y.Q., Wang Z.X., Guo Y.M., 2014. Effect of replacement of corn oil with linseed oil on fatty acids composition and the expression of lipogenic genes in broiler chicken. Czech J. Anim. Sci. 59, 353-364

Chin S.F., Storkson J.M., Alblight K.J., Cook M.E., Pariza M.W., 1994. Conjugated linoleicacid is a growth factor for rats as shown by enhanced weight gain and improved feed efficiency. J. Nutr. 124, 2344-2349

Crespo N., Esteve-Garcia E., 2001. Dietary fatty acid profile modifies abdominal fat deposition in broiler chicken. Poultry Sci. 80, $71-78$

Folch J., Lees M., Sloane Stanley G.H., 1957. A simple method for the isolation and purification of total lipids from animal tissues. J. Biol. Chem. 226, 497-509

Grossmann M.E., Mizuno N.K., Schuster T., Cleary M.P., 2010. Punicic acid is an omega- 5 fatty acid capable of inhibiting breast cancer proliferation. Int. J. Oncol. 36, 421-426

Hennessy A.A., Ross R.P., Devery R., Stanton C., 2011. The health promoting properties of the conjugated isomers of a-linolenic acid. Lipids 46, 105-119

Hontecillas R., O'Shea M., Einerhand A., Diguardo M., BassaganyaRiera J., 2009. Activation of PPAR gamma and alpha by punicic acid ameliorates glucose tolerance and suppresses obesity-related inflammation. J. Amer. Coll. Nutr. 28, 184-195

Igarashi M., Miyazawa T., 2005. Preparation and fractionation of conjugated trienes from alpha-linolenic acid and their growthinhibitory effects on human tumor cells and fibroblasts. Lipids 40, 109-113

Jankowski J., Zduńczyk P., Mikulski D., Juśkiewicz J., Mikulska M., Zduńczyk Z., 2012. Effect of dietary soyabean, rapeseed and linseed oils on performance, slaughter yield and fatty acid profile of breast meat in turkeys. J. Anim. Feed Sci. 21, 143-156

Koba K., Belury M.A., Sugano M., 2007. Potential health benefits of conjugated trienoic acids. Lipid Technol. 19, 200-203

Kohno H., Suzuki R., Yasui Y., Hosokawa M., Miyashita K., Tanaka T., 2004. Pomegranate seed oil rich in conjugated linolenic acid suppresses chemically induced colon carcinogenesis in rats. Cancer Sci. 95, 481-486

McFarlin B.K., Strohacker K.A., Kueht M.L., 2009. Pomegranate seed oil consumption during a period of high-fat feeding reduces weight gain and reduces type 2 diabetes risk in CD-1 mice. Brit. J. Nutr. 102, 54-59

Melo I.L.P., Carvalho E.B.T, Mancini-Filho J., 2014. Pomegranate seed oil (Punica granatum L.): a source of punicic acid (conjugated a-linolenic acid). J. Hum. Nutr. Food Sci. 2, 1024

Morrison W.R., Smith L.M., 1964. Preparation of fatty acid methyl esters and dimethylacetals from lipids with boron fluoridemethanol. J. Lipid Res. 5, 600-608 
Nekooeian A.A., Eftekhari M.H., Adibi S., Rajaeifard A., 2014. Effect of pomegranate seed oil on insulin release in rats with type 2 diabetes. Iran J. Med. Sci. 39, 130-135

Palmquist D.L., 2009. Omega-3 fatty acids in metabolism, health, and nutrition and for modified animal product foods. Prof. Anim. Sci. 25, 207-249

Pietras M.P., Orczewska-Dudek S., 2013. The effect of dietary Camelina sativa oil on quality of broiler chicken meat. Ann. Anim. Sci. 13, 869-882

Saha S.S., Ghosh M., 2012. Antioxidant and anti-inflammatory effect of conjugated linolenic acid isomers against streptozotocininduced diabetes. Brit. J. Nutr. 108, 974-983

Sassano G., Sanderson P., Franx J., Groot P., van Straalen J., Bassaganya-Riera J., 2009. Analysis of pomegranate seed oil for the presence of jacaric acid. J. Sci. Food Agric. 89, 1046-1052

Smulikowska S., Rutkowski A. (Editors), 2005. Recommended Allowances and Nutrition Value of Feedstuffs. Poultry Feeding Standards (in Polish). $4^{\text {th }}$ Edition. The Kielanowski Institute of Animal Physiology and Nutrition, PAS, Jabłonna (Poland) and Polish Branch of WPSA

Subcommittee Energy of the Working Group nr. 2 Nutrition of the European Federation of Branches of the World's Poultry Science Association, 1989. European Table of Energy Values for Poultry Feedstuffs. $3^{\text {rd }}$ Edition. Wageningen (the Netherlands)
Szymczyk B., Pisulewski P., Szczurek W., Hanczakowski P., 2001. Effect of conjugated linoleic acid on growth performance, feed conversion efficiency, and subsequent carcass quality in broiler chickens. Brit. J. Nutr. 85, 465-473

Tsuzuki T., Kawakami Y., Abe R., Nakagawa K., Koba K., Imamura J., Iwata T., Ikeda I., Miyazawa T., 2006. Conjugated linolenic acid is slowly absorbed in rat intestine, but quickly converted to conjugated linoleic acid. J. Nutr. 136, 2153-2159

Yuan G.F., Chen X.E., Li D., 2014. Conjugated linolenic acids and their bioactives: a review. Food Funct. 5, 1360-1368

Yuan G.F., Sinclair A.J., Sun H.Y., Li D., 2009a. Fatty acid composition in tissues of mice fed diets containing conjugated linolenic acid and conjugated linoleic acid. J. Food Lipids 16, 148-163

Yuan G.F., Sun H., Sinclair A.J., Li D., 2009b. Effects of conjugated linolenic acid and conjugated linoleic acid on lipid metabolism in mice. Eur. J. Lipid Sci. Technol. 111, 537-545

Yuan G.F., Yuan J.Q., Li D., 2009c. Punicic acid from Trichosanthes kirilowii seed oil is rapidly metabolized to conjugated linoleic acid in rats. J. Med. Food 12, 416-422

Yasui Y., Hosokawa M., Sahara T., Suzuki R., Ohgiya S., Kohno H., Tanaka T., Miyashita K., 2005. Bitter gourd seed fatty acid rich in $9 c, 11 t, 13 t$-conjugated linolenic acid induces apoptosis and up-regulates the GADD45, p53 and PPAR $\gamma$ in human colon cancer Caco-2 cells. Prostaglandins Leukot. Essent. Fatty Acids 73, 113-119 